\title{
La intérprete de Juan Mayorga \\ La intérprete by Juan Mayorga
}


Eulogio- Falso. Eso que le han contado de mí, es falso. Invíteme a otra de éstas y le contaré las cosas como son. Con limón, por favor, con mucho hielo.

Sonia se va y vuelve con una copa, con limón, con mucho hielo. Eulogio le da un trago largo.

No es verdad que hiciese el Rey Basilio durante diez años. Las leyendas redondean. Lo hice cinco días más tres meses más nueve años. Contando matinales para colegios, quinientas ochenta y una representaciones por todo el país.

Sonia- ¿Cómo se olvida un papel?

Eulogio- ¿Perdón?

Sonia- ¿Cómo se olvida un papel?

Silencio.

Eulogio- La gente siempre pregunta lo contrario: “¿Cómo ha podido meterse todo eso en la cabeza?”. Nunca te preguntan cómo te lo sacas. ¿Periodista?

Sonia- No.

Eulogio- Claro que no, ¿cuándo di mi última entrevista?, ¿quién se acuerda de Eulogio Arenas y de su Rey Basilio? Si no es periodista, ¿qué es? ¿Zoóloga buscando bichos en extinción? ¿Arqueóloga? ¿Qué curiosidad la ha traído hasta mí?

Sonia- Me acordé de este bar. Hace años acompañé a un actor, un actor extranjero, hasta la puerta. Él había oído que era un bar de actores. 
He pensado que, si tenía suerte, podía encontrar a alguien que me ayudase.

Eulogio- ¿Le ayudase a qué?

Sonia- A olvidar un texto.

Eulogio- ¿Eres actriz?

Sonia- Intérprete. No de personajes, de lenguas.

Eulogio- ¿Traductora?

Sonia- Intérprete.

Silencio.

Eulogio- Venimos aquí a bajar la función, si tenemos función, o a quejarnos si no la tenemos. Nos gusta, ya ves qué tontería, porque se llama "El Blanco". Somos infantiles, los actores, si se llamase "El verde" pasaríamos de largo. Tú sabes lo que es un blanco, tener un blanco.

Sonia- Sí.

Eulogio- En la tele interpreté a un traductor de novelas policiacas. Ya, ya sé que no es lo mismo, no es igual traducir libros que traducir personas. Quieres olvidar un texto. ¿Puedo echarle un vistazo?

Sonia- Lo tengo aquí. (Se toca la cabeza.)

Eulogio- Lo tienes en la cabeza. ¿No lo tienes escrito?

Sonia- Escrito en la cabeza. Lo veo tan claro como si lo estuviese leyendo. Eulogio- Lo memorizaste por algo, un examen o lo que sea, y ahora te arrepientes, o te ocupa demasiado espacio.

Sonia- No lo memoricé, lo escuché desde la cabina. A veces trabajamos en cabina, yo le llamo "la caja". Escuchamos por cascos y hablamos 
al micrófono. La gente también nos escucha por cascos. La gente me oye a mí, no al que está hablando. No consigo quitármelo de encima.

Eulogio- ¿Y por qué quieres quitártelo de encima?

Sonia- No me deja pensar en nada más.

Silencio.

Eulogio- ¿Cómo dijiste que te llamas?

Sonia- Sonia.

Eulogio- ¿Me traes otra de éstas, Sonia?

Sonia se va y vuelve con una copa, con limón, con mucho hielo.

Ese lugar, la caja, tiene que ser horrible, ¿no? Estar ahí dentro sola, rodeada de palabras, estar encerrada en una caja de palabras, qué miedo.

Sonia- Normalmente somos dos. Cada media hora nos damos el relevo. Es un trabajo de mucha tensión.

Eulogio- Ya me lo imagino, para volverse loco: escuchar-cambiar-hablar, escuchar-cambiar-hablar. Qué oficio tan extraño, oír palabras y cambiarlas de lengua.

Sonia- Hay oficios más extraños.

Eulogio- Tienes que ser una sabihonda. Eres un coco, ¿eh?

Sonia- No comprendo todo lo que traduzco, y muchas veces traduzco simplezas. Pero a veces te tocan cosas interesantes. Es un trabajo en que todos los días aprendes algo.

Eulogio- Así que a veces dices cosas sin entenderlas. 
Sonia- No podemos saber de todo, ni podemos decir: "Repita eso, que no lo he entendido". Se llama traducción simultánea.

Eulogio- No tienes por qué avergonzarte, Sonia. Yo también digo a veces cosas que no entiendo, en el escenario y fuera del escenario. Todo el mundo dice cosas que no entiende. Si entendiésemos todo lo que decimos, nos volveríamos locos. A veces decimos simplezas, a veces decimos cosas que no entendemos, a veces decimos cosas que más vale no entender.

Sonia- A mí me produce tensión, hablar sin entender. Intento estar preparada, pero un día tienes un ingeniero naval y al día siguiente una bailarina, no puedes ser hoy filósofo y mañana boxeador. A veces es él el que no sabe. Si se expresa mal, ¿̨le mejoro la expresión? ¿Digo lo que ha dicho o lo que ha querido decir? Tú estás ahí, en medio, intentando salir adelante sin que la barca se rompa. Lo único que intento no hacer es médicos, ahí un error puede tener consecuencias terribles. Mi compañero Lauro se niega a traducir chistes sucios. A veces el que habla te ve como un instrumento o ni siquiera te ve, habla sin pensar que tú vas a tener que repetirlo. Pero, salvo los médicos, yo no me pongo límites. Claro que me gustaría estar diciendo siempre frases maravillosas, pero de todo se aprende, incluso de los chistes sucios. Si el otro dice un disparate, lo traduzco como disparate, aunque la gente piense que la loca eres tú, dices algo raro y piensan que tú eres la rara. Lo mejor que puede pasar es que nadie repare en ti, que no se den cuenta de que existes. 


\section{Silencio.}

Eulogio- O sea, que sí eres actriz.

Sonia- ¿?

Eulogio- Si el otro dice "Yo quiero ir a la luna", tú no dices "Él quiere ir a la luna", dices "Yo quiero ir a la luna".

Sonia- Exacto.

Eulogio- Te pones en su lugar, eres él. Dices "Yo" para que se vea a otro, dices "Yo" para desaparecer. Eres actriz. No sólo traduces palabras. Si se ríe, te ríes; si llora, lloras...

Sonia- No.

Eulogio- Deberías probar.

Sonia- Hay compañeros que traducen los gestos, la actitud, los ves cambiar según quién les toque. Si el otro pone cara de preocupado, ellos ponen cara de preocupado. La chulería o la timidez, la traducen también. En mi oficio, hay gente que se cree inteligente porque dice cosas inteligentes de otros.

Eulogio- Igual entre los actores.

Sonia- $\mathrm{O}$ que se creen buenas personas porque traducen a una buena persona.

Eulogio- Igual los actores.

Sonia- Imitan la entonación. Yo pongo la misma voz me toque quien me toque, desde el principio hasta el final.

Eulogio- Qué aburrido. 
Sonia- No soy una actriz. Hago igual mi trabajo sea una víctima o su verdugo. No soy una actriz.

Eulogio- Eres una actriz. Aunque no te rías ni llores, eres una actriz. Y lo tuyo es más difícil que lo mío, porque tú no lo tienes ensayado, tu personaje se hace sobre la marcha. La hostia, ¡un personaje que se hace sobre la marcha! ¿Puedes traerme otra? Tiene que ser la hostia, sobre todo cuando lo tengas al lado. En la caja será otra cosa: estás en la caja y, sin darte cuenta, es él el que está allí dentro. Me imagino la tensión que tiene que haber en esa caja. Tú tienes que escuchar de un modo muy especial. Tienes que concentrarte absolutamente, para que nada te distraiga, para que no exista nada más que las palabras. ¿Me traes o no me traes otra?

Sonia se va. Vuelve con las manos vacías.

Sonia- Soñé con esas palabras y, cuando desperté, todo me parecía extraño. La persona con la que duermo, mi cuerpo, todo me parecía extraño. Silencio.

Eulogio- Ahora entiendo de qué hablas, por fin sé de qué hablas. Las palabras te cambian. A todo el mundo, pero tú y yo estamos más expuestos, los que tenemos estos oficios en que las palabras pasan a través de nosotros. Algunas se te quedan dentro y afectan al modo en que ves a los demás y al modo en que te ves. Has hecho bien en venir a verme, yo te comprendo. Interpretamos palabras y, claro, se nos meten hasta los huesos. Es nuestra vida, tenemos que vivir con ello. 
Sonia- Yo no puedo vivir con ello. No puedo. Vengo de pedir ayuda a mi maestro, pero no ha sabido dármela, o no ha querido. He caminado sin saber dónde ir hasta que se me ha ocurrido que un actor podía ayudarme. Entonces me he acordado de este bar.

Eulogio- Tú lo ves como un hechizo, buscas a alguien que rompa el hechizo, y estás dispuesta a pagar un precio. Has entrado en este bar, aunque no te gusta, y te has acercado a mí, aunque no te gusto. Tampoco yo me gusto, ni me gusta este bar, lo odio, pero cada noche me da aquí hasta el día siguiente. No tengo nada que hacer mañana. Casi nunca tengo nada que hacer mañana. ¿Tú tienes algo que hacer mañana?

Sonia- Mañana voy a acompañar a mi hija al colegio. Luego, tengo que ir a trabajar.

Eulogio- ¿No puede llevarla su padre? ¿O es que no es su padre?

Sonia- Todo está relacionado. Me fui a estudiar el idioma y allí lo conocí. Tengo que ir al aeropuerto a recoger a alguien, a veces también te toca hacer de chófer. Voy a llevarlo a su hotel, a comer, a pasear, lo que él quiera, hasta las siete. Le dan un homenaje. Van a entrevistarlo en el ring, a él y a otro de aquí, para recordar una pelea que tuvieron hace treinta años. En la época fue un acontecimiento. No podré acompañar a mi hija y hacer mi trabajo si no tengo la cabeza limpia. Necesito ayuda.

Silencio. 
Eulogio- Me pasó en La vida es sueño. No sólo entonces, pero nunca como entonces. A veces, al aprender un papel, una frase, una palabra, te toca personalmente. Te hace pensar en tu padre, o en tu hijo, o en ti mismo de niño, en lo que has hecho con tu vida, en lo que deberías haber hecho. Cuando tienes esos trabajos en que las palabras pasan a través de ti, antes o después alguna te estallará dentro. Te estallan porque hay algo dentro de ti, dormido, que esas palabras despiertan. Me pasó en La vida es sueño. En cada función había ocho versos, siempre los mismos, que eran como atravesar el infierno.

Silencio.

Para aprender un papel, memorizo cada escena en un lugar diferente. Es una técnica que, cuando estaba empezando, me enseñó un viejo actor, tan viejo como yo ahora. Una escena la aprendo en una plaza, otra bajo un puente... Luego, en el escenario, pienso en la plaza o en el puente y me viene la escena. Cuando dejé a Basilio, o él me dejó a mí, para olvidarlo, tuve que volver a esos sitios. Volvía a esos sitios y borraba una frase cada día.

Sonia- ¿Cómo se borra una frase?

Eulogio- Desordenando las palabras. Por ejemplo, en lugar de "un monstruo en forma de hombre", "monstruo un forma en hombre de", "forma monstruo hombre en de un"... Cuando lo haces muchas veces, la frase se deshace. Cada día, una frase.

Sonia- Una frase cada día. 
Eulogio- A veces, durante meses, pienso que lo he logrado, que las he echado para siempre. Siempre vuelven. En el momento que menos lo espero. En un sueño, de pronto, digo: "Su madre infinitas veces,/entre ideas y delirio/del sueño vio que rompía/sus entrañas atrevido/un monstruo en forma de hombre;/y entre su sangre teñido,/la daba muerte naciendo/víbora humana del siglo”. En un sueño. Más vale que lo aceptemos, Sonia, estamos poseídos.

Silencio.

Sonia- Engañé a la gente. Cambié palabras.

Silencio.

Eulogio- No vuelvas a esa caja en que entran y salen palabras. Quédate aquí, aunque no seas actriz. Yo diré a todos éstos que eres actriz. Te echarían a patadas si descubriesen que no eres actriz, pero yo sabré esconderte.

Sonia- No puedo quedarme. Voy a acompañar a mi hija al colegio.

Eulogio- Te arrepentirás.

Sonia abraza a Eulogio y sale a la calle. Camina por la noche de la ciudad.

4

Lauro- Shsss. Nos ha costado mucho dormir al niño. 
Sonia- Perdón. Discúlpame, Lauro, sé que no son horas de llegar a una casa. La verdad es que esperaba que me llamases tú. He esperado tu llamada toda la tarde.

Lauro- ¿? ¿Ha pasado algo?

Sonia- ¿Cómo puedes preguntarme eso? Tú estabas allí.

Lauro- ¿?

Sonia- La tercera conferencia.

Lauro- La tercera conferencia fue tuya.

Sonia- Estabas conmigo en la caja.

Lauro- En la cabina, si no es mi turno, estoy más sordo que una tapia. No escucho al compañero, pongo la cabeza en otra cosa. Mentalmente no estoy allí. No aguantaría. No sé cómo he aguantado esta tarde, Sonia, tres horas sin parar.

Sonia- Te lo agradezco mucho, Lauro. Mucho. Entonces, ¿no sabes de qué estuvo hablando ese hombre?

Lauro- Sé lo que luego se comentaba en los pasillos. ¿Para esto has venido a estas horas? No has venido para esto.

Sonia- ¿Qué se comentaba en los pasillos?

Lauro- Nada bueno. Pero no sabría decirte de qué habló. Los que lo criticaban, tampoco parecían saberlo. Uno dijo: "Éste se ha equivocado de lugar y de momento". Durante la comida, nadie quería sentarse a su lado. Nadie quiere compartir mesa con el demonio.

Sonia- ¿? ¿Por qué dices eso? 
Lauro- Es una forma de hablar.

Sonia- ¿Por qué "demonio"?

Lauro- Sonia, mañana empiezo a las ocho, necesito descansar. Tú también.

Sonia- Quiero que me cuentes lo que recuerdas. Desde que ese hombre subió al estrado hasta que volvió a sentarse entre el público.

Lauro- Te juro que no presté atención. Ni siquiera recuerdo cómo era, si era alto o bajo, gordo o flaco, no lo recuerdo...

Sonia- ¿ ¿Te estás burlando?

Lauro- Claro que no. Yo no me lo tomo con tú, Sonia. Hago mi trabajo y punto. Doy un servicio. Cuando salgo de la cabina, me olvido.

Sonia- ¿De verdad no oíste nada? ¿Ni una palabra?

Lauro- Ni una palabra.

Sonia- Crees que no hice bien mi trabajo, ¿̨eh?, es eso.

Lauro- No puedo juzgar tu trabajo. Aunque hubiese oído tus palabras, no podría juzgarlas sin conocer las suyas.

Sonia- Me mirabas como si desaprobases lo que estaba haciendo.

Lauro- No. Me vas a perdonar, Sonia, tengo que volver con el niño.

Sonia- ¿Te ha pasado alguna vez que un material te haya hecho pensar cosas que nunca hubieras imaginado pensar?

Lauro- ¿'Sabes qué vamos a hacer, Sonia? Vamos a averiguar en qué hotel se alojan esos filósofos. Averiguamos el hotel, llamamos a la habitación de ese hombre y le pides que te repita la conferencia, para ti sola. Le va a alegrar saber que su conferencia interesó a alguien. En eso 
sí me fijé: nadie le hizo ni una pregunta, ni un comentario... El niño se ha despertado.

Sonia- Necesito ayuda.

Silencio.

Lauro- Lo que necesitas es descanso. Tómate unos días.

Sonia- No puedo tomarme unos días, tengo que resolver esto esta noche. Mañana voy a acompañar a Elena al colegio y luego voy a ir a trabajar. Un viejo. Van a entrevistarlo en el mismo ring en que combatió hace treinta años, a la misma hora que hace treinta años. Fue una pelea salvaje, he visto imágenes tremendas. Cuando el combate parecía decidido, un golpe lo cambió todo. Va a ser difícil para Elena, encontrarse con las otras niñas. La han expulsado durante una semana. Se pegó con otra y tuvo que pedir perdón en público.

Lauro- Estoy libre por la tarde. Puedo hacerlo por ti. No puedo llevar a tu hija al cole, pero puedo encargarme de ese boxeador.

Sonia- Eres un mierda. ¿Lo sabes, que eres un mierda?

Lauro- ¿Qué dices? Estás en mi casa... Eh, eh, ¿qué haces? Quítame las manos de encima.

Sonia- Yo te pido ayuda y tú... Creía que eras mi amigo.

Lauro- No puedo ayudarte, Sonia. No conozco a ningún psiquiatra bueno, si es que hay psiquiatras buenos.

Sonia- Qué hijodeputa eres. 
Lauro- No soy tu amigo, pero te ayudaría si supiera cómo hacerlo. Te he observado muchas veces en la cabina, y fuera de ella. El modo en que te relacionas con el trabajo es anormal. Deberías cambiar de trabajo. Centrarte en tu hija. Los niños son otra cosa. Los niños no son sólo palabras.

Silencio.

Sonia- Me estás mintiendo, lo escuchaste todo, no entiendo por qué me mientes. Tenemos que estar juntos en esto.

Silencio.

Tengo miedo. Cambié el final.

Silencio.

Lauro- No puedes quedarte aquí. Tengo miedo por el niño.

Silencio. Sonia sale. Camina por la noche de la ciudad.

5

Sonia entra en la cabina de traducción. La observa. Toma asiento ante el micrófono. Se pone los cascos. Sus ojos quieren cerrarse. Parece oir algo por los cascos. Tras escucharlo, habla al micrófono como intérprete. Luego habla al micrófono como Sonia. Y asi sucesivamente: escucha, habla, habla.

Sonia- ¿Qué hace aquí a estas horas, Sonia? ¿No debería estar en su casa, si es que tiene casa? ¿O es que vive en esa caja? 
Sonia- He probado otras cosas esta noche. Ya no me queda nada más que probar. He forzado tres puertas hasta llegar aquí, donde empezó todo.

Sonia- Quiere intentarlo de nuevo, jes eso? Quiere que repita mi conferencia e intentarlo otra vez. Comprendo que esté insatisfecha. Yo lo estoy. Hizo mal su trabajo.

Sonia- Usted no puede juzgar mi trabajo. A menos que conozca mi idioma. ¿Conoce mi idioma?

Sonia- Sé qué efecto deberían haber provocado mis palabras y vi el que provocaron las suyas. Yo envié un mensaje y usted lo convirtió en otra cosa. Puso en mi boca palabras que no pronuncié, que jamás pronunciaría.

Sonia- Tenía que proteger a la gente.

Sonia- ¿Es su trabajo, proteger a la gente?

Sonia- No lo había sido hasta hoy.

Sonia- ¿Cree que la gente no puede cuidar de sí misma?

Sonia- No parecían personas fuertes. También pensé que podían repetir sus palabras allí donde luego fuesen, y que otras personas débiles podían escucharlas. ¿Conoce o no conoce mi idioma? ¿De dónde es usted? Al oírlo, pensé: "Habla como si fuera extranjero de su propia lengua”. Luego pensé: "Quizá no sea su lengua. Quizá lo que oigo sea una traducción".

Sonia- La vi sufrir. Sufrí por usted. 
Sonia- Me sentía tonta, rabiosa, por no entender. Me parecía que tampoco usted entendía del todo. Es la primera vez que pronunciaba esa conferencia, ¿verdad?

Sonia- ¿Cree que la pronuncié para usted? ¿Cree que la estaba esperando a usted y, al reconocerla, dije lo que dije, para usted?

Sonia- Me sentí utilizada. Violada.

Sonia- Usted pudo salir de esa caja y decir a todos, claramente: "No soy capaz de este trabajo". También pudo guardar silencio. Si no se atrevía a lo uno ni a lo otro, pudo fingirse enferma e irse. Pero decidió quedarse y traicionar su oficio, traicionarme a mí, traicionar a los que habían venido a escucharme. ¿Para protegerlos? No. Usted no quería proteger a la gente, quería protegerse a sí misma. Pero ninguna trampa hubiera podido protegerla. Lo supe en cuanto empezó a hablar, usted no estaba luchando contra mí, luchaba contra sí misma. Y cuanto más luchaba, más evidente le era que mis palabras le pertenecían. No venían de fuera, Sonia, esas palabras, estaban dentro de ti. Desde la primera frase te diste cuenta de que también tú estabas hablando, de que por primera vez en tu vida estabas hablando realmente. Después de tanto balbucear, al fin habías encontrado tu voz. Después de tanto tiempo hablando con palabras prestadas, estabas hablando con tus propias palabras. Pero tuviste miedo de ellas y cambiaste el final. No ha sido suficiente y, aunque la gente te da miedo, has salido a la noche de la ciudad a la búsqueda de algo -otras palabras, un mal golpe - que te devuelva a 
aquel tiempo en que todavía no habías oído esas palabras, palabras que han cambiado tu relación con tu vida y con la vida de los otros, palabras que pueden hacer daño a otros, palabras que pueden dañar a personas que quieres. Tienes miedo por las personas que quieres. Miedo de eso que se extiende desde tu interior. De quien tienes que proteger a los demás es de ti misma.

Silencio.

Sonia- Mañana tengo que acompañar a mi hija al colegio y a un boxeador que combatió hace años en esta ciudad. Me he preparado. He visto el combate tantas veces que podría contarlo con los ojos cerrados.

Sonia- Tus ojos quieren cerrarse. Tus ojos no pueden cerrarse. Esas palabras que no dijiste no te dejan descansar, Sonia, no descansarás hasta que las digas. La noche se acaba, Sonia. Ya has probado todo lo demás.

Silencio. Intenta hablar. Fracasa. Se quita los cascos. Sale de la caja. Camina por la noche de la ciudad.

6

En la mitad izquierda de un ring, sentados ante sendos micrófonos, Sonia y Marài. Sonia escucha a través de un auricular la pregunta que tiene que traducir para Marài.

Sonia- (Al público.) Señor Marài, ¿qué siente al pisar otra vez este ring, treinta años después? 
En voz más baja, acercando su cabeza a la de Marài, Sonia traduce para éste la pregunta. Dándose cuenta de que Marài oye mal, Sonia acerca su cabeza a la de él y vuelve a traducirle la pregunta. Silencio. Marài se aproxima al micrófono para contestar, pero finalmente acerca su cabeza a la de Sonia y le habla al oído. Asi se comunicarán en lo sucesivo Sonia y Marài: en voz baja, con las cabezas muy próximas. Tras escuchar lo que le dice Marài, Sonia habla al público:

Estoy nervioso.

Sonia espera a ver si Marài dice algo más. Recibe otra pregunta, habla al público:

¿Había vuelto a encontrarse con su rival, señor Marài?

Sonia habla a Marài; Marài se vuelve hacia la otra mitad del ring y luego habla a Sonia; Sonia al público:

Al abrazarlo, me he dado cuenta de que no es tan alto como lo recordaba. O habrá menguado, habrá encogido más que yo. Nos hemos encontrado muchas veces desde entonces. En sueños. En sueños eres enorme. En sueńos eres un gigante.

Sonia espera a que Marài diga algo más. Recibe otra pregunta; habla al público:

Señor Marài, cuando subió al ring, ¿`abía que iba a ser su último combate?

Sonia habla a Marài; Marài a Sonia; Sonia al público:

No fue mi último combate. Mi último combate es hoy. A eso he venido. 
Silencio. Sonia recibe otra pregunta; habla al público:

Señor Marài, ¿cree usted en Dios?

Sonia habla a Marài; Marài hace un gesto de rechazo de la pregunta o de Dios; Sonia recibe otra pregunta; habla al público:

Señor Marài, ¿qué tiene que decir a los que todavía hoy sostienen que fue un combate amañado?

Sonia habla a Marài; Marài a Sonia; Sonia al público:

Intentaron comprarme. Está aquí, el que me quiso comprar, es el que ha organizado todo esto, ha querido darme la mano, su voz no ha cambiado. No voy a darte la mano, hijodeputa. Yo no me vendo. No soy una puta.

Sonia recibe inmediatamente otra pregunta; habla al público:

Señor Marài, ¿no cree que el árbitro debió parar el combate?

Sonia habla a Marài; Marài a Sonia; Sonia al público:

El árbitro no pudo parar el combate. Nada hubiera podido parar el combate.

Silencio. Sonia recibe otra pregunta; habla al público:

Señor Marài, ¿qué es lo primero que pensó al salir del coma?

Sonia habla a Marài. Marài se vuelve hacia la otra mitad del ringy habla a Sonia; Sonia habla al público, para lo que de vez en cuando tendrá que pedir silencio a Marài.

Me di cuenta de que no estaba de pie y de que no estabas conmigo. No estabas conmigo y yo quería cerrar los ojos otra vez, pero cuando los cerraba veía un resplandor. Oía a la enfermera moverse 
por la habitación. Cuando la oí salir, me levanté, busqué a tientas la ropa y salí a la calle, no quería salir a la calle desnudo. La calle estaba llena de pasos de personas que huían y de pasos de personas que perseguían. Volví a mi habitación, me quité la ropa y esperé de pie a que la enfermera volviese. Cuando entró, dio un grito y corrió a avisar. Luego vinieron días de gente entrando y saliendo, discutían sobre qué hacer conmigo, mi mujer, mis hijos, el médico, la enfermera, todos sentían vergüenza por mi derrota. Un día la enfermera me dijo que me iba a casa y que de vez en cuando iría a visitarme. Nunca me visitó. Aprendí a moverme por la casa. A contar los pasos. Desde la cama hasta la puerta de la habitación: cuatro pasos. Desde la puerta de la habitación hasta la puerta de la cocina: siete pasos. Desde la puerta de la cocina hasta el grifo: dos pasos. Me di cuenta de cómo suena un vaso de cristal cuando lo meten en otro. Me di cuenta de cosas en las que nunca me había fijado. Momentos en los que no me había fijado. A veces me enfurecía y rompía cosas, pero cada vez comprendía más. Comprendía mi vida, cada momento, por fin.

Silencio. Sonia recibe otra pregunta; habla al público:

Señor Marài, ¿no piensa usted que los niños ahora tienen demasiada libertad?

Silencio. Marài habla a Sonia, quien habla al público. En algún momento, Marài se descalzará. En otro, mostrará un viejo mapa. 
En varios momentos, Sonia parecerá recibir por los auriculares instrucciones que decidirá no obedecer.

Voy a descalzarme. No es una falta de respeto, es todo lo contrario. No tengo nada contra vosotros. Espero que Sonia me esté traduciendo bien. Cuando el avión ha aterrizado, me han acompañado a recoger mi maleta y me han llevado hasta la salida. Ella me ha saludado en mi idioma, por mi nombre, pero ¿cómo sabía que soy quien le han dicho que soy? ¿Y si Marài murió de aquel combate? "Soy su intérprete, señor Marài, me llamo Sonia. He tenido que traer a mi hija conmigo, no quería entrar en el colegio". La nińa estaba esperando en el asiento de atrás. “¿Dónde vamos?", he preguntado a Sonia. "Al hotel. ¿̨O quiere usted comer antes, señor Marài?". "No quiero ir al hotel ni a comer. Quiero ir a estos tres sitios". Y le he enseñado este mapa. "Es un mapa de hace treinta años, Sonia. Quiero ir a los sitios marcados. Y quiero que me digas por dónde vamos pasando. ¿Por qué conduces tan despacio?". "No he podido dormir", ha dicho, "no quiero que nos hagamos daño". De camino, me ha explicado lo que esperabais de mí. Que no hablase solamente para listos, que diese respuestas cortas pero no muy cortas, que intentase ser ameno, que contase anécdotas porque a la gente le gustan las anécdotas. Me ha dicho todo lo que queríais que dijese, pero yo no he resistido treinta ańos para obedecer. He tenido mucho tiempo para pensar, a oscuras. A veces me enfurecía y rompía cosas. Rompí un espejo, mis hijos 
no lo entendían: ¿por qué rompe un espejo, si está ciego? Rompí muchas cosas hasta que empecé a pensar. Yo nunca había pensado. Empecé pensando en cosas que ya no podía ver pero que aún recordaba, luego pensé en cosas que nunca he visto. No es falta de respeto, es todo lo contrario. Antes de cada combate, subía al ring descalzo para sentirlo. Echo de menos el tacto del ring, el olor del ring. Este ring está muy limpio, hace mucho que nadie sufre aquí, pero no conseguirán borrar el olor de los cuerpos. Espero que Sonia no me cambie las palabras, sobre todo al final. No he venido a decir las palabras que habéis venido a oír.

Viendo que Marài no va a añadir nada, Sonia pide otra pregunta, que tarda en llegar. Habla al público:

Señor Marài, tuve la desgracia de presenciar aquella carnicería. Mi padre me trajo a ver el combate y no se lo he perdonado. No he vuelto a asistir a ninguno, ni lo haré nunca. Recuerdo cómo se miraban: pensé que querían matarse. ¿Querían matarse?

Sonia habla a Marài; Marài tarda en hablarle a ella; lo hará acabando con un gesto que envuelve al público.

Quién sabe si morimos aquella noche. Quién sabe si somos fantasmas. Quién sabe si vosotros sois fantasmas.

Sonia recibe otra pregunta, pero Marài se precipita a hablarle. Sonia habla al público:

La noche antes del combate no podía dormir y salí a la calle. Llovía. No conocía esta ciudad, no conocía a nadie. Llovía cada vez más 
fuerte, contra mi rostro, no me sentía capaz de defenderme de la lluvia, no me sentía capaz de defenderme. Quería pedir ayuda, pero ¿y si pedía ayuda y nadie me la daba? Tenía un mapa de la ciudad, con él llegué hasta la puerta de este lugar en que al día siguiente iba a combatir. Alguien se me acercó a través de la lluvia y me dijo: “¿Necesita ayuda?”. No en mi lengua, ni en la suya, con un gesto. Las fotos me habían hecho pensar en él como alguien mayor. Me pareció que él no me esperaba tan viejo, también a él las fotos lo habían confundido. Me preguntó si quería entrar aquí, él sabía cómo hacerlo. Me ayudó a secarme la cara. Peleamos. Reímos. Me acompañó hasta mi hotel y esperó a que me durmiese y al día siguiente pude pelear. Silencio.

También yo creo a veces que fue un sueño, ese encuentro la noche antes del combate. Si fue un sueño, fue verdad.

Silencio. Marài hace a Sonia un gesto indicando que quiere decir algo más, pero luego no encuentra palabras para hacerlo. Sonia recibe otra pregunta. Habla al público:

Para acabar, señor Marài, ¿quiere decir algo al hombre con el que peleó en este ring hace treinta años?

Sonia habla a Marài, quien replica sin dejarle acabar. Sonia habla al público:

Yo diré cuándo acabar.

Sonia termina de hacer la pregunta interrumpida por Marài. Marài se vuelve hacia la otra mitad del ring y luego habla a Sonia. En 
cierto momento, comenzará a hacer gestos pugilisticos, hasta acabar poniéndose en pie y moviéndose como si boxease contra un rival. Sonia habla al público:

Chocan nuestros guantes en el centro del cuadrado y tus pies empiezan a saltar, izquierda-derecha, delante-atrás, yo no levanto los míos, no voy a desperdiciar ni una pizca de fuerza, voy a dejar que tú despilfarres la tuya en esa exhibición infantil, izquierdaderecha, delante-atrás, voy a tener paciencia, voy a observarte hasta que tú mismo me muestres cómo vencerte, delante-atrás, izquierda-derecha, bailas sin atacar, sabes que estoy esperando tu error, el público protesta, quieren golpes y sangre, quieren verte romperme y eso es bueno para mí, es tu gente y vas a obedecerles, lanzas tu derecha y el público aúlla, tu izquierda, tu derecha, me abrazo a ti, echo todo mi peso sobre ti, tus puños se pierden en mi cuerpo como en un montón de arena, no sé qué me gritan pero sé que son insultos, das dos pasos atrás buscando espacio para armar un buen golpe, bajas los puños, te ofreces, "¿Me tiene miedo, abuelo?”, disparo la izquierda contra tu mandíbula, no esperabas un puño tan rápido, te tambaleas, caes lentamente, el árbitro cuenta uno dos tres cuatro, apoyas una rodilla sobre la lona, seis siete, el público ruge al verte en pie, no estás seguro de estar en pie, sólo ves sombras, ¿¿cuál de esas sombras soy yo?, lanzo mi izquierda contra tu rostro, la derecha contra tus costillas, tengo que acabar cuanto antes, de tu ceja brota sangre, si vuelves a caer no podrás 
levantarte, agitas los brazos para mantenerme alejado, no puedo dejar que te recuperes, un-dos, un-dos, levanta el brazo, muchacho, no quiero hacerte más daño, no voy a abrir la boca aunque me falte el aire, daría el alma por un trago de agua, una esponja en la nuca, camino hacia ti fingiendo vigor, la mano izquierda en la mejilla, amago con la derecha, disparo la izquierda, la esquivas, no cierro a tiempo el hueco y tu puño estalla en mi oreja, tengo que mantenerme en pie, no sé si estoy en pie, sólo veo sombras, ¿cuál de esas sombras eres tú?, surges de todas partes, mi rostro arde, el público se levanta gritando tu nombre, qué ganas de arrodillarme, qué ansia de arrancarme el corazón, un-dos, un-dos, cada golpe es un puñal, ¿por qué dejas de pegarme?, ¿por qué caminas hacia atrás?, pides al árbitro que pare el combate, pido al árbitro que no pare el combate, avanzo hacia ti con la boca abierta, jadeante, un cuchillo me atraviesa las sienes, no sabía que se pudiese sufrir tanto, te golpeo y me golpeas, la sangre que nos cubre es la misma sangre, las bocas saben a una sola sangre, ya no vemos el mundo, ya no oímos el mundo, te apoyas en las cuerdas porque las piernas no te sostienen, tus brazos cuelgan como ramas rotas, sólo podré dar un golpe más, eres mío pero un golpe lo cambiaría todo, lo que te queda de vida lo pones en tu puño izquierdo, mis ojos se deshacen en la oscuridad y el silencio, el público, el mundo, tu rostro, todo desaparece, todavía no sé que he caído y qué tú has roto a llorar. 
Silencio. Marài saca algo que muestra hacia la mitad derecha del ring. Habla a Sonia; Sonia al público:

Yo no he estado casi nunca en el mundo. Aquella noche sí. Sólo he estado en el mundo, completamente en el mundo, aquella noche, aquí, contigo. Estaba realmente en el mundo, absolutamente. Eso te lo debo a ti. Haber estado en el mundo una vez, realmente. Te he traído algo. Cuando supe que no volvería a ver, empecé a regalar cosas. Cosas que amo y que ya no puedo ver, quiero que las tengan personas que pueden verlas. Puede que alguno de ellos, cuando vea su regalo, piense en mí. El tuyo tenía que ser especial, un regalo para la única persona con la que he estado realmente. Es difícil encontrar en el mundo a alguien con quien estás realmente, la mayoría muere sin haberlo encontrado. Yo tardé mucho en entender, durante años no entendí qué había ocurrido realmente. Pocos pueden decir: conozco mi deseo; pocos entienden su deseo. No queríamos matarnos. Queríamos morir. Aquella noche, aquí. Seguimos aquí, aquella noche, solos tú y yo, en un combate sin fin. Sé que sientes mis puños cada noche, sé que tienes memoria de cada uno de mis golpes. Tu regalo tenía que ser el más importante. Lo reconoces, ¿̇verdad? El último golpe fue tuyo. Luego vino el tiempo hasta que desperté y el tiempo después del despertar. En el tiempo de después, las palabras importan más que antes, en este tiempo dependemos absolutamente de las palabras. He tenido 
tiempo para buscarlas. He encontrado las palabras y he venido a decirlas. El deseo es la única verdad. Sólo el deseo es verdad. Besa a Marài en los ojos y se echa a dormir en el ring, en posición fetal. Duerme. Oscuro. 
